\title{
Development of Rutherford-type Cables for High Field Accelerator Magnets at Fermilab
}

\author{
N. Andreev, E. Barzi, E. Borissov, L. Elementi, V.S. Kashikhin, V. Lombardo, A. Rusy, D. Turrioni, \\ R.Yamada, A.V. Zlobin
}

\begin{abstract}
Fermilab's cabling facility has been upgraded to a maximum capability of 42 strands. This facility is being used to study the effect of cabling on the performance of the various strands, and for the development and fabrication of cables in support of the ongoing magnet $R \& D$ programs. Rutherford cables of various geometries, packing factors, with and without a stainless steel core, were fabricated out of $\mathrm{Cu}$ alloys, NbTi, $\mathrm{Nb}_{3} \mathrm{Al}$, and various $\mathrm{Nb}_{3} \mathrm{Sn}$ strands. The parameters of the upgraded cabling machine and results of cable $R \& D$ efforts at Fermilab are reported.
\end{abstract}

Index Terms-cabling machine, critical current degradation, superconducting strand, Rutherford cable.

\section{INTRODUCTION}

$\mathrm{R}$ UTHERFORD cable has played a key role in establishing $\mathrm{NbTi}$ accelerator magnet technology, widely used in modern high energy accelerators thanks to its excellent mechanical, electrical and thermal properties. Superconducting (SC) dipoles and quadrupoles based on this cable design were successfully used in the Tevatron, HERA, RHIC and LHC. A new generation of accelerator magnets being developed at Fermilab [1], other U.S. Laboratories [2], and in Europe [3] is using Rutherford cables based on $\mathrm{Nb}_{3} \mathrm{Sn}$ strands. The work on Rutherford cables based on some other superconductors, such as $\mathrm{Nb}_{3} \mathrm{Al}$ and BSCCO-2212, for future accelerator magnets is also in progress [4], [5].

The SC cable R\&D program at Fermilab focuses on two important issues: the study of the effect of cabling on the performance of the various strands (design, materials), and the development and characterization of cables in support of the ongoing magnet R\&D programs. The availability of a cabling facility is an important part of this effort as it allows a faster turnaround with respect to using cabling facilities in industry, which are more oriented towards large scale cable production. A few years ago Fermilab purchased a compact cabling machine and re-spooler developed and fabricated at IHEP (Protvino) [6]. The capability of these machines was originally limited to a $1 \mathrm{~mm}$ strand and a 28-strand cable, which was used in the first $\mathrm{Nb}_{3} \mathrm{Sn}$ dipole models [7]. Since then, the

Manuscript received August 28, 2006.

This work was supported by the U.S. Department of Energy.

All Authors are with the Fermi National Accelerator Laboratory, Batavia, IL 60510 USA (N. Andreev phone: 630-840-2071; fax: 630-840-3369; e-mail: andreev@fnal.gov). machine was significantly upgraded to meet the growing needs of the conductor and magnet R\&D programs. This paper reports on the status of the cabling facility and presents the most recent results of cable R\&D performed at Fermilab.

\section{DESCRIPTION OF CABLING FACILITY}

The cabling facility consists of a compact cabling machine, re-spooler, sets of forming fixtures and measuring devices. Operations include re-spooling of strands from the vendor to the cabling machine spools, transposition of strands into a cable and forming of the cable with a rectangular or keystone cross-section, control of the cross-section size under small compression, and cable spooling onto the pick-up reel.

After purchase, the cabling machine had only one motor, which provided motion to the main 28-spool wheel with its planetary mechanism, to the caterpillar, and to the cable spooler. The synchronization of these various systems was provided by several gear boxes. The gears were designed for a 28-strand cable made of $1 \mathrm{~mm}$ strand with a fixed 14 degree transposition angle. The forming fixtures and the measurement devices were also designed for these cable specifications. To expand the range of cable designs the machine kinematics was later upgraded. These upgrades included the development and installation of a new 42-spool wheel, independent motors to move main wheel, caterpillar and cable spooler, new electronics and software for motor synchronization, and a more sophisticated cable size control.

The new 42-spool wheel was developed, fabricated and installed by experts from IHEP (Protvino). The new wheel was designed to fit into the same space occupied by the previous 28-spool wheel. The wheel capacity was increased thanks to using slightly smaller spools and a better compaction of the wheel components. A picture of the new 42-spool wheel after installation on the cabling machine is shown in Fig. 1.

Four motors were used to deliver the motion directly to each system, eliminating the need for mechanical gears and drive trains. Motor synchronization is based on servo motor systems. The speed and position of the various systems is controlled with a PLC controller. The caterpillar motor has a servo driver that is set in an "electronic gearing follower" mode. In such mode, the driver controls the motor position as a function of the signal of an encoder placed next to the main 
wheel. This signal is multiplied by a gearing ratio parameter that is fed directly into the driver itself. The pickup spool synchronization is controlled by the PLC. The use of the independent synchronized motors instead of gears eliminated the problem of backlash and mechanical wear, resulting in a precise and repeatable control, and reducing machine maintenance. The cabling machine parameters after the upgrades are summarized in Table 1.

TABle I. CABLING MACHINE PARAMETERS

\begin{tabular}{ll}
\hline \hline Parameter & Value \\
\hline Number of strands & 42 \\
Strand diameter range & $0.3-1.5 \mathrm{~mm}$ \\
Planetary ratio & $0,+1,-1$ \\
Main engine power & $1.34 \mathrm{~kW}$ \\
Maximum wheel speed & $40 \mathrm{rpm}$ \\
Maximum strand tension & $30 \mathrm{~N}$ \\
Maximum cable pulling force & $5000 \mathrm{~N}$ \\
Spool size DxdxH & $150 \times 96 \times 105 \mathrm{~mm}$ \\
Cable reel size DxdxH & $400 \times 260 \times 175 \mathrm{~mm}$ \\
\hline \hline
\end{tabular}

The re-spooler had been designed to perform strand respooling and cutting to length. To reduce the risk of strand breaks during cabling, re-spooling is performed under a tension provided by two driving drums kinematically connected by the magnetic clutches. The main re-spooler parameters are shown in Table 2. The re-spooler was later equipped with a motor and driver to synchronize spool motion and obtain an adjacent turn-to-turn placement for strands in an ample size range.

TABLE II. RE-SPOOLER PARAMETERS.

\begin{tabular}{ll}
\hline \hline Parameter & Value \\
\hline Strand diameter range & $0.3-1.5 \mathrm{~mm}$ \\
Re-spooling speed & $10-120 \mathrm{~m} / \mathrm{min}$ \\
Tension in the controlled section & $50-350 \mathrm{~N}$ \\
Take-up and supply tension & $20-50 \mathrm{~N}$ \\
Spool weight capacity & $32 \mathrm{~kg}$ \\
Drive motor power & $0.23 \mathrm{~kW}$ \\
\hline \hline
\end{tabular}

The machine uses $\sim 90 \mathrm{~mm}$ long mandrels (Fig. 2), optimized to reduce friction and provide good strand stability during cabling [8]. For fabrication of cables with a core, the mandrels used in this case have grooves machined on the upper flat surface of mandrel [9]. A flexible mandrel connection allows its self-aligning with respect to the cable forming fixture.

The primary forming fixture shown in Fig. 3 forms a cable with a rectangular cross-section and a low packing factor. It consists of two wide vertical rolls with variable gap, and of two thin horizontal rolls. The final precise keystone crosssection of a cable is formed using a two-roll die with variable gap, fixed keystone angle and cable width.

Cable thickness during fabrication is measured under a transverse compression using a device with a PC based data acquisition system for continuous control in the cabling process (Fig. 4). Typical variations of cable width and thickness along the length of a keystoned cable are \pm 0.011 and $\pm 0.003 \mathrm{~mm}$ respectively. Work on a new cable size measurement system based on laser micrometers has been started.

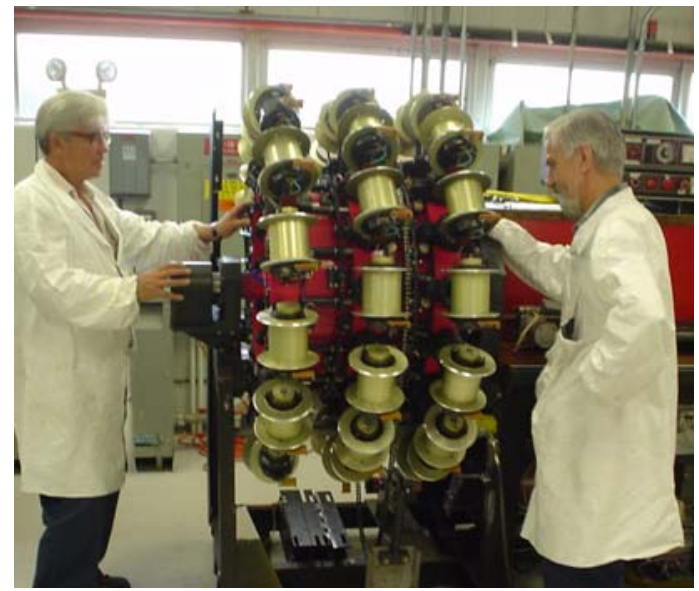

Fig. 1. New 42-spool wheel installed in the cabling machine.

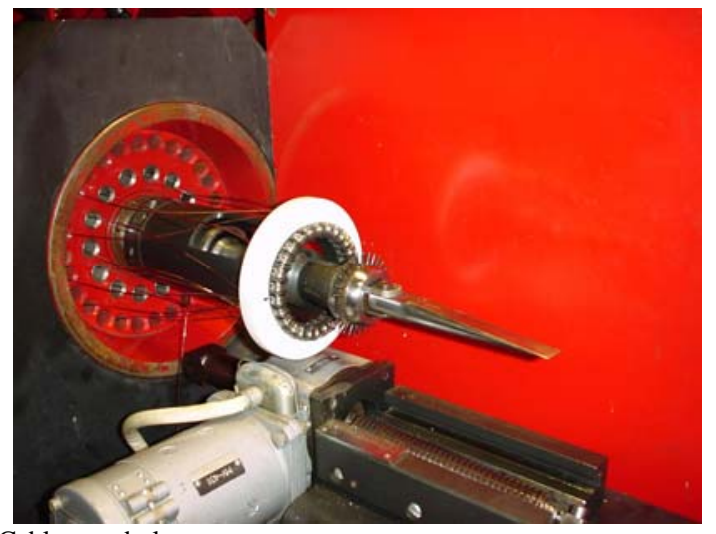

Fig. 2. Cable mandrel.

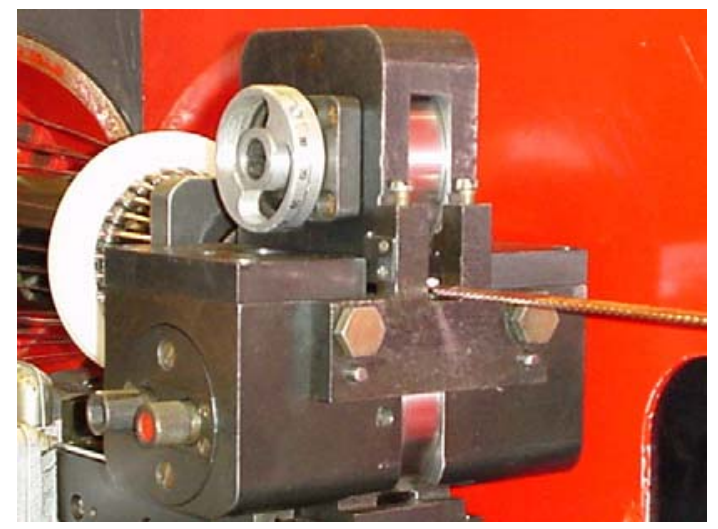

Fig. 3. Rectangular cable forming fixture.

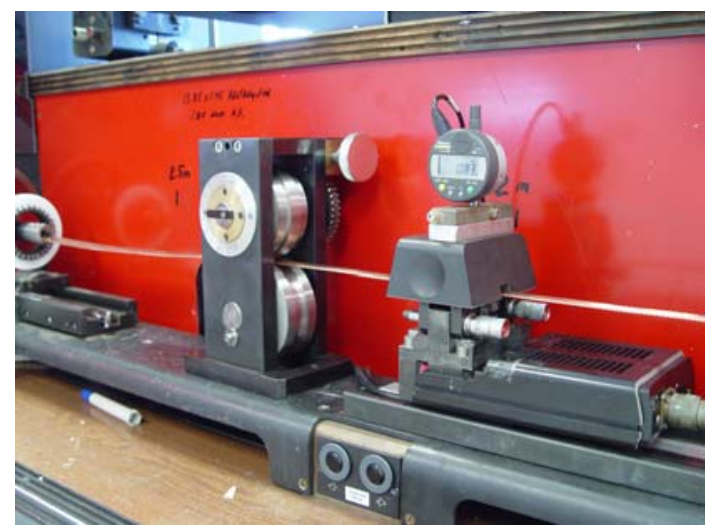


Fig. 4. Cable sizing fixture and automatic measuring device.

\section{CABLE FABRICATION AND STUDIES}

\section{A. Pitch Angle Range Study}

A study of the possible pitch angle range for Rutherford cables was started using $1 \mathrm{~mm}$ hard $\mathrm{Cu}$ strand and 28-strand cable design. Optimization of the cable pitch angle provides more mechanically stable cable and possibly lower critical current degradation due to less severe deformation of the wire at the edges of the cable [10]. $100 \mathrm{~m}$ of right-handed and lefthanded cables with pitch angles between 9 and 19 degrees were fabricated. It was found that below 12 degree the cable shows mechanical instability and that at 16 degree popped strands, sharp edges and crossovers occur. Crossovers appeared and disappeared with a good reproducibility with the pitch angle. This study was performed also using 27 and 39 strand cables made of $0.7 \mathrm{~mm} \mathrm{Cu}$ Alloy68 strand. In this case the stable range of transposition angles was within 9-16 degrees. A study of the pitch length on the strand critical current degradation will follow.

\section{B. Strand Number Optimization}

Two keystoned cables with 27 and 28 strands, using $1 \mathrm{~mm}$ NbTi strands were fabricated to study the effect of even and odd number of strands in a cable of same cross-section. Analysis and comparison of these two cables demonstrated that, although the cable with an odd number of strands has a slightly smaller packing factor, it remains mechanically stable and has a smaller value and variation of the minor edge compaction. The analysis of sub-element deformation inside strands at the cable edges demonstrated better results for the cable with odd number of strands.

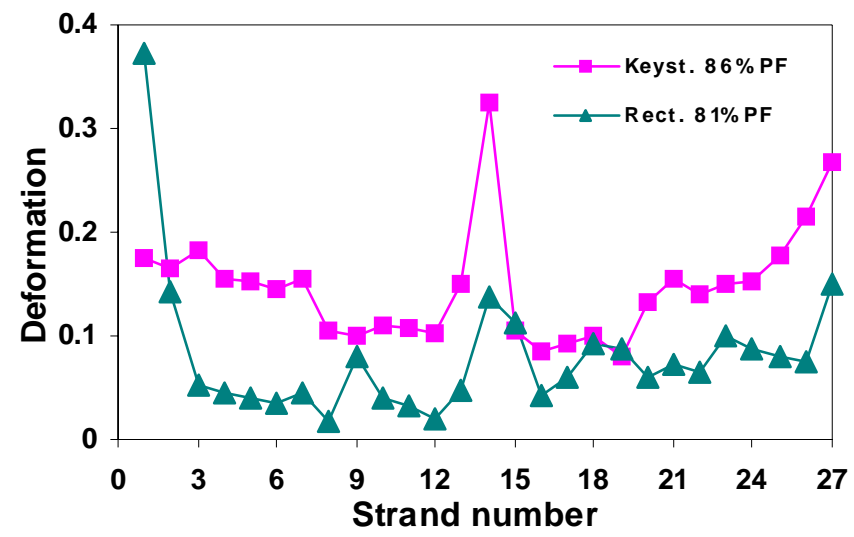

Fig. 5. Strand deformation as a function of position in 27-strand cables.

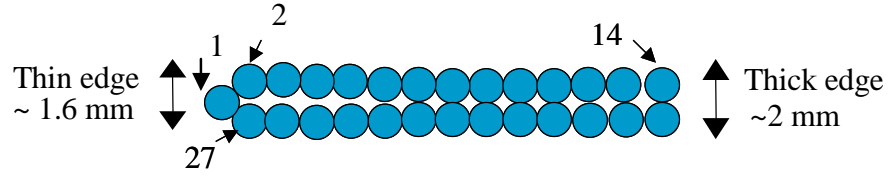

Fig. 6. Scheme of the strand numbering used in a cable.

\section{Strand Deformation}

Fig. 5 shows the deformation of each strand as a function of its location in the cable (Fig. 6) in a keystoned and rectangular 27-strand cables made of $1 \mathrm{~mm} \mathrm{Nb}_{3} \mathrm{Sn}$ strands produced using the Restack Rod Process (RRP) (see also Section III.D). The definition that was used for strand deformation is:

$$
\text { Deformation }=\left(d_{\max }-d_{\min }\right) / d_{0},
$$

where $d_{\max }$ and $d_{\min }$ are the longest and shortest diameters measured through the strand center, and $d_{0}$ is the original round strand size. Within the limited statistics, there is already an indication that in both cables the largest deformation values are found at both cable edges. The average strand deformation is lower in the least compacted cable. However, despite this cable being rectangular, its end strands saw even larger deformation values than their keystoned counterparts. These results are so far consistent with critical current degradation in $\mathrm{Nb}_{3} \mathrm{Sn}$ depending on packing factor [11]. Continuing these studies on more cable sizes and geometries will allow determining empirical laws correlating packing factor with average strand deformation in a cable, and to establish an upper limit for the keystone angle.

\section{RRP 108/127 Cable Fabrication and Test}

Based on the results of strand number optimization, a $70 \mathrm{~m}$ piece of keystoned 27-strand cable with $1 \mathrm{~mm}$ RRP strands of 108/127 sub-element design was fabricated, and round and extracted strands were tested. A small racetrack and a costheta half-coil were fabricated using $\sim 15 \mathrm{~m}$ and $\sim 50 \mathrm{~m}$ long pieces of this cable. The small racetrack was tested and reached its predicted short sample limit [12]. More recently, a $300 \mathrm{~m}$ long piece of this cable was fabricated for a 4-m long cos-theta coil [14].

\section{E. $\mathrm{Nb}_{3} \mathrm{Al}$ Cable Development}

Feasibility studies of $\mathrm{Nb}_{3} \mathrm{Al}$ Rutherford cable based on a strand produced using the Rapid Heating-Quenching Treatment (RHQT) process and stabilized with $\mathrm{Cu}$ with the ion deposition method were performed in collaboration with NIMS (Japan). First, a $\sim 60 \mathrm{~m}$ long piece of 27-strand $\mathrm{Nb}_{3} \mathrm{Al} / \mathrm{NbTi}$ hybrid cable, with both rectangular and keystoned cross-sections, was fabricated. Studies of this cable provided feedback to NIMS that helped improving the strand design and coating procedure. Then a $\sim 30 \mathrm{~m}$ piece of rectangular 27-strand $\mathrm{Nb}_{3} \mathrm{Al}$ cable with $83 \%$ to $90 \%$ compaction was fabricated (Fig. 7). The round and extracted strands, and cable samples that were tested showed small cabling degradation. A small racetrack based on $\mathrm{Nb}_{3} \mathrm{Al}$ cable and the wind-and-react method was fabricated and successfully tested [13].

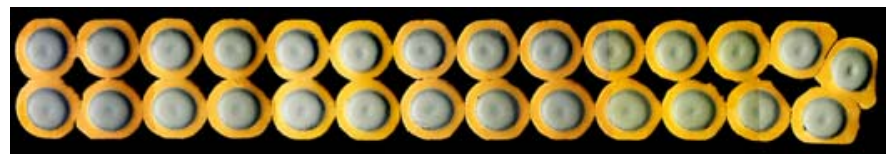

Fig. 7. Rectangular $\mathrm{Nb}_{3} \mathrm{Al}$ cable with $83 \%$ packing factor.

\section{F. PIT Cable for $\mathrm{Nb}_{3} \mathrm{Sn}$ Magnet Technology Scale Up}

The $\mathrm{Nb}_{3} \mathrm{Sn}$ accelerator magnet technology scale up program at Fermilab uses 2-m and 4-m cos-theta dipole coils [14] made of cables with $\mathrm{Nb}_{3} \mathrm{Sn}$ strands produced by ShapeMetal Innovation (SMI) based on Powder-in-Tube (PIT) technology. The $1 \mathrm{~mm}$ strands used for the 2-m long coil include billets 187 to 193 (4.7 km total length) with 192 filaments. A similar strand was used in 1-m long $10 \mathrm{~T}$ dipole models developed at 
Fermilab [14]. A new PIT strand design (billet 207) with 288 filaments and larger critical current density was proposed by SMI for use in the 4-m long coil. A 50-m long strand sample of this billet was used for round strand test and for fabricating a 27-strand cable together with strands from standard billets 187 to 193 . The two different strand designs were tested and compared round, and after cabling. Some of the results including critical current $\mathrm{I}_{\mathrm{c}}$, $\mathrm{n}$-value, instability current $\mathrm{I}_{\mathrm{s}}$ and RRR of the round and extracted strand tests are presented in Table III.

The $\mathrm{J}_{\mathrm{c}}(4.2 \mathrm{~K}, 12 \mathrm{~T})$ of billets 187 to 193 ranged from 1.8 to $1.9 \mathrm{kA} / \mathrm{mm}^{2}$. As expected, the $\mathrm{J}_{\mathrm{c}}(4.2 \mathrm{~K}, 12 \mathrm{~T})$ of billet 207 was about $10 \%$ higher, reaching $2.1 \mathrm{kA} / \mathrm{mm}^{2}$. However, after reaction, several Sn bursts were found on the extracted strand edges from billet 207. No Sn bursts were found on extracted strands from billets 187 to 193. The critical current degradation of billet 207 ranged between $21 \%$ and $31 \%$ at 12 $\mathrm{T}$. The $\mathrm{I}_{\mathrm{c}}$ degradation at $12 \mathrm{~T}$ of billets 187 to 191 ranged between $4.4 \%$ and $6.8 \%$, i.e. similar to that of the strands used in the model magnets. The causes of the Sn bursts and larger degradation in the new PIT strand need to be understood before using it for the $\mathrm{Nb}_{3} \mathrm{Sn}$ technology scale up.

TABLE III. EXTRACTED STRAND TEST RESULTS AT 4.2 K

\begin{tabular}{cccccc}
\hline \hline Strand ID & Sample & $\mathrm{I}_{\mathrm{c}}(12 \mathrm{~T}), \mathrm{A}$ & $\mathrm{n}(12 \mathrm{~T})$ & $\mathrm{I}_{\mathrm{s}}(\mathrm{A}), \mathrm{A}$ & $\mathrm{RRR}$ \\
\hline \multirow{2}{*}{187} & Round & 715 & 40 & $>1775$ & 268 \\
& Extracted & 673 & - & $>1750$ & 255 \\
\multirow{2}{*}{190} & Round & 679 & 40 & $>1775$ & 344 \\
& Extracted & 649 & 45 & $>1775$ & 294 \\
\multirow{2}{*}{191} & Round & 708 & 47 & $>1750$ & 363 \\
& Extracted & 660 & - & - & 279 \\
\hline \multirow{2}{*}{207} & Round & 823 & 47 & $>1775$ & 212 \\
& Extracted & 652 & - & 1400 & 95 \\
& Extracted & 652 & - & 1350 & 167 \\
\hline \hline
\end{tabular}

Note: $1800 \mathrm{~A}$ is the Power Supply maximum current

\section{G. Cable for LARP Magnet $R \& D$.}

Tools to produce the cable used in LARP technology quadrupoles (TQ) and long quadrupoles (LQ) were developed and tested at Fermilab. Cable fabrication and measurement tooling was developed for two cable designs with keystone angles of 0.9 and 1.3 degree. The cable development was performed in two steps. First, for each keystone angle practice cables with 27 and 28-strands were fabricated using $0.7 \mathrm{~mm}$ hard $\mathrm{Cu}$ to optimize the cable geometry. Then, cables of the same designs were fabricated out of $\mathrm{Nb}_{3} \mathrm{Sn} \mathrm{RRP}$ and Modified Jelly-Roll (MJR) strands. The MJR strand had been used in the first LARP quadrupole models.

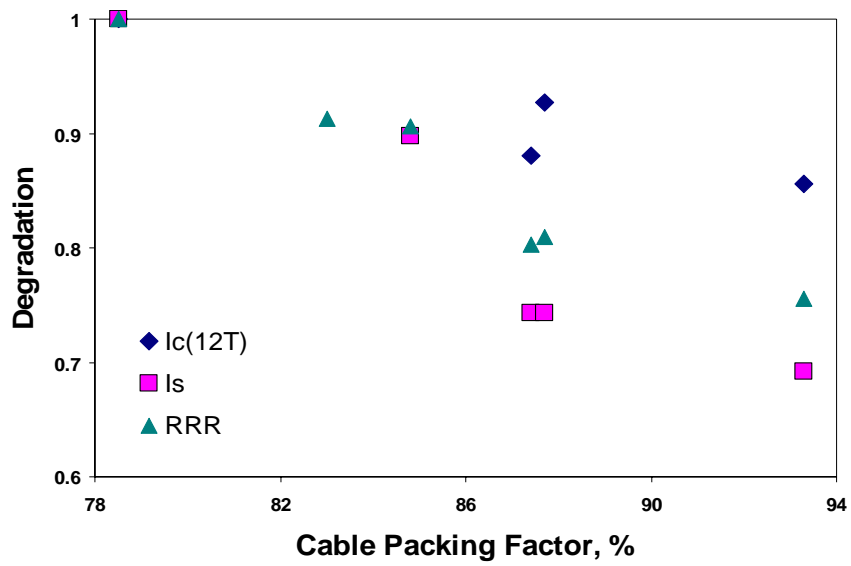

Fig. 9. Cabling degradation at $4.2 \mathrm{~K}$ for nominal TQ cable at $12 \mathrm{~T}$ and $4.2 \mathrm{~K}$.

The cabling degradation of strand parameters relative to those of the virgin strand is shown in Fig. 9 as a function of the cable packing factor for TQ cables with 27 and 28 MJR strands and keystone angle of 0.9 degree. The measured $I_{c}, I_{S}$ and RRR degradation was the same as that of similar cables fabricated at LBNL [15].

\section{CONCLUSIONS}

Fermilab's cabling facility has been upgraded and commissioned to a maximum capability of 42 strands. The performance of new RRP and PIT $\mathrm{Nb}_{3} \mathrm{Sn}$ strand designs with larger number of sub-elements (filaments), and of $\mathrm{Nb}_{3} \mathrm{Al}$ strand was tested with respect to the cabling process. This provided feedback to strand vendors. Production included cables for the $\mathrm{Nb}_{3} \mathrm{Sn}$ technology scale up and short model programs at Fermilab. This cabling facility can now be used as a second cable production line for LARP magnet R\&D.

\section{ACKNOWLEDGEMENT}

The authors would like to thank S.S. Kozub, V.V. Sytnik and technical staff of Physics and Technical Department (IHEP, Protvino) for 42-spool wheel design and fabrication, V. Smirnov and A. Vyatkin (IHEP, Protvino) for wheel installation and commissioning, T. van Raes (Fermilab) for cable manufacturing and sample preparation.

\section{REFERENCES}

[1] A.V. Zlobin et al., "R\&D of $\mathrm{Nb}_{3} \mathrm{Sn}$ Accelerator Magnets at Fermilab", IEEE Trans. on Appl. Supercond., Vol. 15, No. 2, June 2005, p.1113.

[2] S. A. Gourlay, "High Field Magnet R\&D in the USA," IEEE Trans. on Appl. Supercond., Vol. 14, No.2, June 2004, p.333.

[3] A. Devred et al., "High Field Accelerator Magnet R\&D in Europe," IEEE Trans. on Appl. Supercond., Vol. 14, No.2, June 2004, p.339.

[4] A. Devred et al., "High-Field Superconducting Magnet R\&D Aimed at LHC Luminosity Upgrade”, this conference.

[5] E.W. Collings et al., "Bi2212/Ag-based Rutherford cables: production, processing and properties”, Superc. Sci. Technology, 12 (1999), p.87.

[6] E.R. Borisov, A.N. Surkov, "On Designing and Building Equipment for a Wide-Scale Production of SC Transposed Cable for UNK", IEEE Trans. on Magnetics, Vol. 28, No.1, January 1992, p. 686.

[7] G. Ambrosio et al., "Development of the $11 \mathrm{~T} \mathrm{Nb}_{3} \mathrm{Sn}$ Dipole Model at Fermilab”, IEEE Trans. on Appl. Supercond., Vol. 10, No. 1, March 2000, p.298. 
[8] E.R. Borisov, A.N. Surkov, "Design and Technological Peculiarities of a Small-Size Equipment for the Production of SC Transposed Cable for UNK”, Preprint IHEP 91-80, Protvino 1991.

[9] J.D. Adam et al., "Rutherford Cables with Anisotropic Transverse Resistance”, IEEE Trans. on Appl. Supercond., Vol. 7, No. 2, June 1997, p. 958.

[10] J.M. Royet, R.M. Scanlan, "Development of scaling rules for Rutherford type superconducting cables”, IEEE Trans. on Magnetics, Vol. 27, No. 2, March 1991, p. 1807.

[11] E. Barzi et al., "Strand Critical Current Degradation in $\mathrm{Nb}_{3} \mathrm{Sn}$ Rutherford Cables”, IEEE Trans. on Appl. Supercond., Vol. 11, No. 1, March 2001, p. 2134.

[12] E. Barzi et al., "Performance of $\mathrm{Nb}_{3} \mathrm{Sn}$ RRP Strands and Cables Based on a 108/127 Stack Design", this conference.

[13] R. Yamada et al., "Feasibility Study of $\mathrm{Nb}_{3} \mathrm{Al}$ Rutherford Cable for High Field Accelerator Magnet Application”, this conference.

[14] F. Nobrega et al., " $\mathrm{Nb}_{3} \mathrm{Sn}$ Accelerator Magnet Technology Scale Up Based on Cos-theta Coils", this conference.

[15] E. Barzi et al., "Round and Extracted Strand Tests for LARP Magnet R\&D”, IEEE Trans. on Appl. Supercond., Vol. 16, No. 2, June 2006, p.319. 